\title{
Cropland Mapping Expansion for Production Forecast: Rainfall, Relative Humidity and Temperature Estimation
}

\section{Prodipto Bishnu Angon}

Faculty of Agriculture, Bangladesh Agricultural University, Mymensingh, Bangladesh

Email: angonbishnubau@gmail.com

\section{Imrus Salehin}

Department of CSE, Daffodil International University, Dhaka, 1207, Bangladesh

Email: imrus15-8978@diu.edu.bd

\author{
Md. Mahbubur Rahman Khan \\ Department of Food and Process Engineering, Hajee Mohammad Danesh Science \& Technology University, Dinajpur, \\ Bangladesh \\ Email: emonmahbub47@gmail.com
}

\section{Sujit Mondal}

Faculty of Agriculture. Patuakhali Science and Technology University, Patuakhali, Bangladesh

Email: sujitmondal.pstu@gmail.com

Received: 27 July 2021; Accepted: 26 August 2021; Published: 08 October 2021

\begin{abstract}
In the modern era agriculture development is the highly contribute field of food security. Data Science is one of the top analysis experimental methods for forecasting and mapping synchronize. In our study, we experiment with three major parameters (Rainfall, Relative Humidity and Temperature) that can be affected crop production rate as well as area-based mapping. To complete the procedure, the cluster groping and prediction system has created a machine learning BOT combined analysis system. Bangladesh and its 13 areas with 46 years of data have visualized with proper analysis and build up a 2D map of each separate production area. Multi Linear Regression (MLR) and KMean Clustering is the main key point algorithm for the production analysis. Experiment analyzing, we can see that some elements of our environment are closely associated with the productivity of the crop. An untactful environmental change on parameters (Rainfall, Humidity, and Temperature) reduces agricultural productivity by 32-38\%. Developed model accuracy $91.25 \%$ forecasting methodological analysis for production mapping and prediction. Extreme population food security has ensured ICT and Agriculture combine BOT \& EVPM method is essential for the scientific world. This study will allow farmers to choose the proper crop in the right environmental condition, which will play a key role in strengthening the economy of the country.
\end{abstract}

Index Terms: Cropland Mapping, Data Science, Agriculture. Forecasting, Production system, Rainfall.

\section{Introduction}

Climate change has a huge impact on a country's economy [1]. This is a cause for concern, especially when a country's agricultural system is largely dependent on climate. As the farmers of Bangladesh don't use modern machinery in agriculture, the crop production of this country has become very much dependent on nature[2,3]. It depends on adequate rainfall, temperature, relative humidity, etc[4]. There is no substitute for food for human survival, and this food production actually depends on the improvement of agriculture. Technology on the other hand is a huge blessing in people's lives. In today's world, the introduction of information technology in agriculture has led to great improvements in this field. Food security is currently a major concern. With all these considerations in mind, we are going to make an integration between crop production and Data Science for information technology[5,6]. We have worked out the 3 most essential parameters (Rainfall, Relative Humidity and Temperature) for grain production. These have a significant impact on the production of jute and rice. The climate change in recent times has led to variations in Jute and Paddy cultivation in many parts of Bangladesh [7]. This study analyzed the relationship between the variability 
of these parameters of nature with grain production. Farmers have to depend on nature for crop production every year. The amount and duration of seasonal rainfall, temperature, and relative humidity are a big concern for farmers [8]. All the facilities of agriculture in different parts of the country, the use of modern agricultural machinery, the practice of water irrigation are still minimal. Agriculture is the main occupation of this country. About $87 \%$ of rural people depend on agriculture for their livelihood-The World Bank [9]. Food production is generally reduced 4.4\% when the amount of seasonal average rainfall is reduced by $10 \%$ [10]. Rainwater is supplied nutrients required for crop growth [11]. Farmers do not know which crop will produce a good yield in which place. Precipitation and moisture vary from one place to another. In one climate combination, one crop grows well [12]. The purpose of our paper is to find suitable areas for that suitable crop and to inform the farmers about it through a mapping system. So far crop pedicures in this country have not been delivered after extensive research on crop's output, precipitation, temperature, and moisture. Although different parameters of climate and crop yield are constantly recorded. Also, it is seen that crop mapping of this country was not done based on crop production. Considering the importance of climate parameters, it is significant to understand their duration and quantity for improving crop production. Through which the data is collected from the last few years and proposed mapping of cropland by regression analysis based on certain crops. Through which it will be understood how much land in which part of the country crops of this country are cultivated and the amount of their production. As a result, it is easy to understand which crop is cultivated more in a given area and which area is suitable for cultivating which types of crop. In this study, the main novelties are as given below:

(1) Future production is analyzed through some key parameters (2) Full analysis formation we have applied Data science advance mixed-method and algorithm (3) Clustering unsupervised method is applied for different data key point groping and analysis for next result. (4) Supervised learning used for multivariable forecasting analysis and cropland mapping. (5) Cropland detection and mapping data analysis based.

In recent years, we have provided future projections by integrating production figures with precipitation, moisture, and temperature data in various places so as to let farmers know in advance what the yield of a certain crop is going to be in a specific field. Farmers can take the actions necessary to increase productivity.

\section{Literature Review}

The impacts of climatic stresses on crop production are growing up globally. A huge amount of experimental research reveals the correlation between climatic variation and long-term impacts on crop yields. A synthesized extensive range of pilot studies is exhibited to estimate the crop yield changes resulting from the marginal and combined impacts of rainfall, temperature, $\mathrm{CO} 2$ concentration including adaptation strategies. Adaptation among the parameters could have a potential effect on crop yield and when exploring the climate change impacts on crop yield, the effect of CO2 should not be neglected [13]. The irrigated cropland indicates effective subsidence against climate change than non-irrigated cropland. The planning authority and the producer's community must prioritize reallocating the cropland, adapting drought-resistant high-yielding varieties, shifting planting dates and developing new cultivation processes to eliminate the risk of climate-changing variables [14].Seasonal alteration in the magnitude of rainfall and temperature affecting the agricultural production sector. Developing countries are experiencing food insecurity for a massive population growth rate. Therefore, Agriculture production must be adaptive to mitigate the threat of climate change [15]. The alteration in rainfall pattern and air temperature is resulting inconsistency in atmospheric conditions. Then alteration in the photosynthesis process is taking place, which is affecting crop production. Future research and implementation in the agriculture sector must be focused on reducing the variability of temperature, and uncertain precipitation [16].The ecological sustainability and food security of the world are hampering by extreme weather circumstances including imbalanced precipitation, increasing temperature variation, droughts, floods, soil erosion. The ensuing climatic conditions are likely to reduce paddy production, though it depends on the variety of the rice [17].Genomic selection, Single Nucleotide Polymorphism genotyping, and trait mapping providing feasible crop yield. Genetically modified crops could be a solution to climate change which can grow fast under extreme environmental stresses (High-temperature stress, salinity stress, drought stress) [18]. An increase in long-term temperature and annual rainfall is significantly enhancing agriculture production in Bangladesh. Annual temperature variability in Bangladesh is not altering dramatically as noticed in temperate regions of the world. Floodplain agro-ecological zones of Bangladesh are showing a higher production rate except for low-lying floodplain and coastal plain croplands [19]. The antithetical effects of climate change on crop production and the effects on crop yields due to changes in parameters (temperature, rainfall, and humidity) have been explored. The intense temperature has a subversive impact on wheat production. Elsewhere, the effect of rainfall on wheat yield is positive. To assure food security in the country and control the devastating implications of climate change on crops. They have suggested developing new varieties of seeds that can provide maximum yield even at extreme temperature levels [20]. Four analytical schemes: (statistical regressions, global grid-based, local point-based models, and field-warming experiments) have been adopted to measure the implications of temperature on four appointed crop yields to ascertain worldwide food availability. Considering the cropland region and geographical condition from the outcome attained, prospective predictions have been made for the 
intended yield in the subsequent seasons. By using this concept food scarcity will face no uneven enhancement of the global population [21]. The relevance between temperature, humidity, and rainfall over three seasons of 35 years in the southern region of Bangladesh has been explored. This analysis helped to find out about cropping methods and the influences of climate variation on crop production in this area. In the coastal districts of Bangladesh, farmers who produce rice are most affected by climate change. Thereby, farmers are forced to change the cropping pattern. Hence, we need to take some new techniques (the dyke cropping system; salt and flood-tolerant varieties; and floating bed vegetable cultivation) to address climate change influences and ensure food security [22]. Climatic inconstancy and agronomic cultivation are liable for changes in the crop's water use efficiency (WUE) in semi-arid areas of northern China. Each crop has the elasticity to synthesize the water use efficiency (WUE). Although it is not adequate to sustain the requisite water level at a posterior period, it can be exaggerated by realizing drought stress release and practicing feasible agronomic. A breakdown of this capacity would occur for disharmonious agricultural practices and climate change. The water use efficiency (WUE) diagram has been formed so that crop resilience can be regulated by farmers by implementing proper farming practices regardless of climate change [23]. Modern and feasible data on wheat research in Bangladesh in the context of global warming and the potential barriers to the use of advanced technology in wheat cultivation due to climate change have been discussed explicitly. Continuously increasing demand for wheat, emphasis should be laid on wheat cultivation to assure food security for this growing population of the country. However, the farmers of Bangladesh have faced various intimidations for prospective wheat production. Reducing global warming, inventing new varieties, and applying them properly are proper solutions to these problems [24]. The impacts of climate change on farmland values in seven agricultural regions of Bangladesh have been studied by applying the Ricardian model. Flood and rainfall levels play a positive role in reducing the value of Farmland. This research shows that the role of sustainable adaptation strategies in maintaining agricultural productivity and farmland value in Bangladesh in the face of climate change is undeniable [25]. The implication of global climate change on agricultural production and appliance to mitigate climate change to attain the prospective yield has been emphasized. Over the past few decades, there had been a variety of human-organized activities that threaten the environment and cause climate change. Thereby, global warming is increasing the amount of carbon dioxide and erratic rainfall. High temperatures and carbon dioxide cause fatal damage to agricultural production and global food security that pose a threat to our future generations. In the coming decades, it is imperative to address the adverse effects of climate change and take appropriate action to ensure food security [26]. Therefore, to mitigate the adverse effect of climate change, an adaptive agro-ecological environment is indispensable. The present analysis would express the climatic variation effect on the agro-production zone of Bangladesh.

\section{Systematic Workflow}

The potential future effect of global climate change is a major concern now [27]. A systematic flowchart based on EVPM (Environmental Variable Production Model) is described below to analyze the significant change in agriculture production due to climatic stresses (Fig 1.). Preliminary planning and research on challenges in agricultural production is the initial approach of this study. Then data is explored regarding the primary planning. After observing the data, specific crops of the regions is selected, based on our objective. Then sorting the dataset and preparing the sorted data for further analysis. The climatic stresses of the region are identified and selected, which is affecting crop production. After that, the pre-processed data is combined with the climate-changing parameters. In the middle of processing, combined data has gone through several well-known algorithms. Regression analysis is used for cropland mapping. Then k-means clustering algorithm is used to determine the agro ecological prediction by allocating the nearest cluster. Finally, various aspects of the correlation between agricultural production and climate change reveals. Further integrating ways are discussed at the completion portion. 


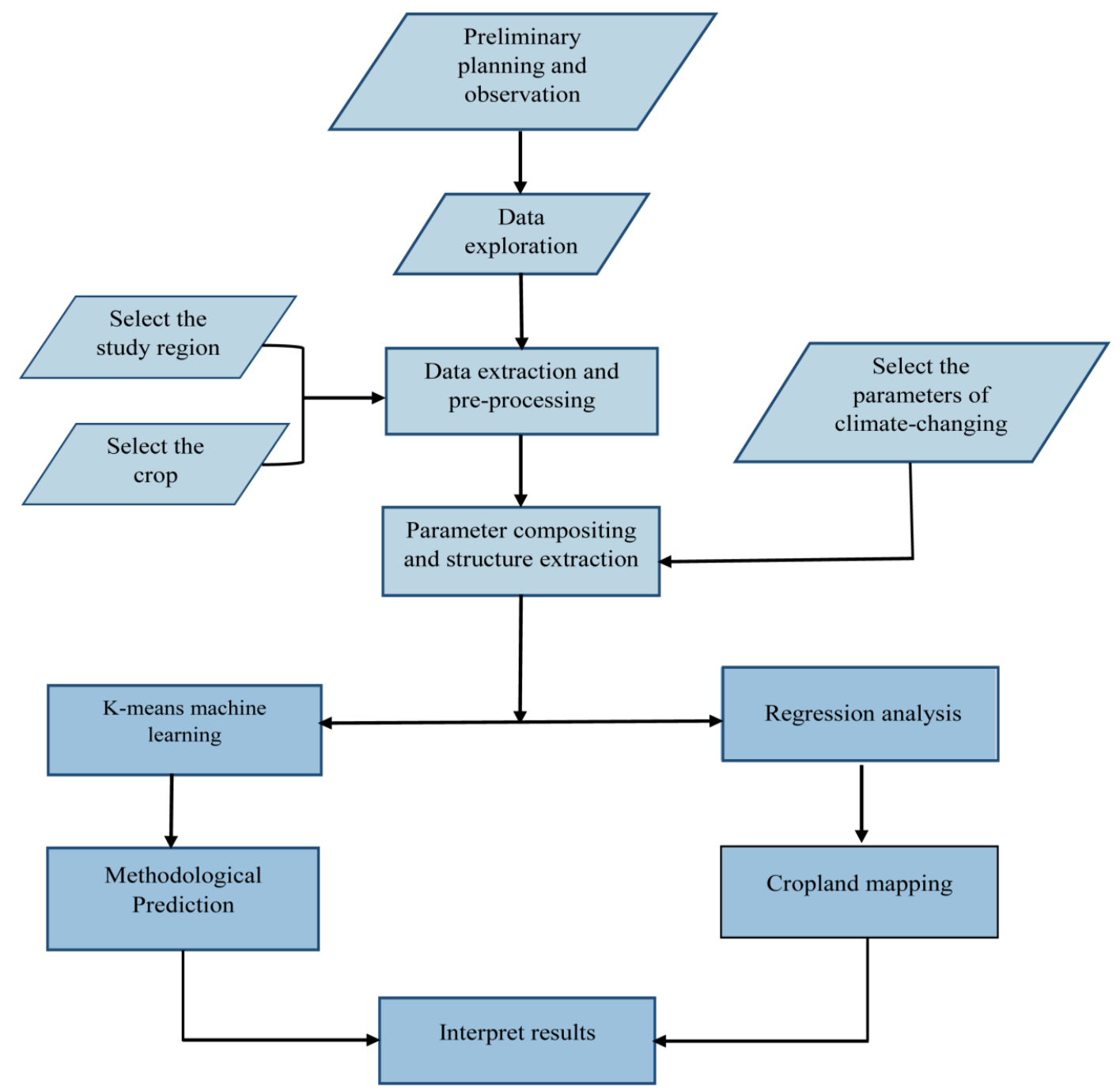

Fig.1. EVPM model for a conceptual framework

\section{Data Exploration}

Data exploration is a vital task for an analytical study [28]. To make a proper analysis, the method has been divided into several steps. The selection of the right crop has been based on some characteristics. These criteria are: crops that have been in the field for at least 120 days. Crops that are affected by climate change (Temperature, Relative Humidity and Rainfall) have been selected so that the study can be more efficient. They must be productive grain.In this session first, the field of the area is selected, then the dataset is acquired from Kegel, The Bangladesh Bureau of Statistics (BBS), and The World Bank. Lastly, all the data has been integrated together for analysis.

\subsection{The region of the study}

The regions of Dhaka, Tangail, Comilla, Dinajpur, Jessore, Bogra, Rajshahi, Chittagong, Khulna, Sylhet, Mymensingh and Rangpur play amomentousrole in the agricultural economy of Bangladesh for paddy and jute cultivation. Thereby, we have selected these areas for the study. 


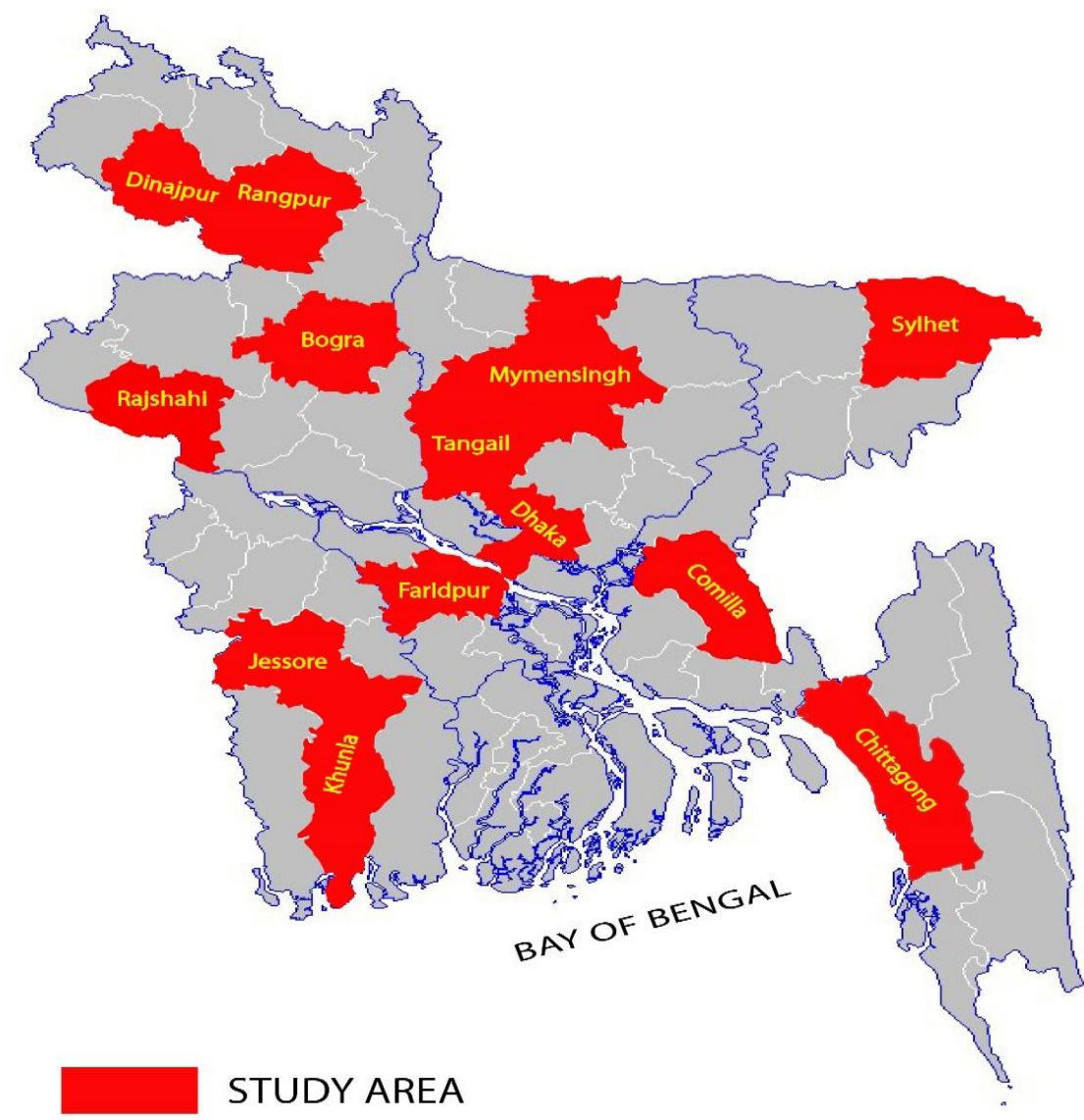

\section{DISTRICT}

Fig.2. Regional Study area of Bangladesh

Among them, Dhaka is situated in tropical climatic conditions. More rainfall occurs in summer than winter. The annual mean temperature in Dhaka is $25.3^{\circ} \mathrm{C} \mid 77.5^{\circ} \mathrm{F}$, yearly precipitation is $2055 \mathrm{~mm} \mid 80.9$ inches, and relative humidity is $75 \%$. Chittagong also has a tropical climate. Most of the months have adequate rainfall. The annual mean temperature in Chittagong is $25.3^{\circ} \mathrm{C} \mid 77.5^{\circ} \mathrm{F}$, yearly rainfall is $2777 \mathrm{~mm} \mid 109.3$ inches andyearly mean humidity is $73.7 \%$. The weather of Khulna is cloudy and troublesome. Mostly clear and hot conditions are seen in the dry season. The annual mean temperature in Khulna is $27^{\circ} \mathrm{C} \mid 80.6^{\circ} \mathrm{F}$. Total precipitation is $1290.5 \mathrm{~mm} \mid 50.8$ inches and annual mean humidity is $75 \%$. Rajshahi has periodic moist and arid weather. There is reasonable precipitation, considerable humidity, and aerial temperature. The highest average temperature is $36^{\circ} \mathrm{C} \mid 97^{\circ} \mathrm{F}$. Yearly total precipitation is about $1448 \mathrm{~mm}$ | 57.0 inches and yearly mean humidity is $77 \%$.

Table 1. Different Parameter's units in study areas

\begin{tabular}{|c|c|c|c|c|c|}
\hline \multirow[t]{2}{*}{ Area } & \multicolumn{2}{|c|}{ Temperature (yearly) } & \multicolumn{2}{|c|}{ Rainfall (yearly) } & \multirow{2}{*}{$\begin{array}{l}\text { Relative } \\
\text { Humidity } \\
\text { (yearly) \% }\end{array}$} \\
\hline & ${ }^{\circ} \mathrm{C}$ & ${ }^{\circ} \mathrm{F}$ & $\mathrm{mm}$ & inches & \\
\hline Dhaka & 25.3 & 77.5 & 2055 & 80.9 & 75 \\
\hline Chittagong & 25.3 & 77.5 & 2777 & 109.3 & 73.7 \\
\hline Khulna & 27 & 80.6 & 1290.5 & 50.8 & 75 \\
\hline Rajshahi & 30 & 86 & 1448 & 57.0 & 77 \\
\hline Mymensingh & 29 & 84.2 & 2249 & 88.54 & 76 \\
\hline Sylhet & 23.6 & 74.5 & 5048 & 198.7 & 77 \\
\hline Rangpur & 24.3 & 75.7 & 2497 & 98.3 & 79 \\
\hline
\end{tabular}


Mymensingh is situated in average climatic conditions. The arid season is usually thermal and the moist season is overcast. The highest mean temperature is $32.1^{\circ} \mathrm{C} 189.8^{\circ} \mathrm{F}$. Yearly total rainfall is $2249 \mathrm{~mm} \mid 88.54$ inches and yearly mean humidity is $76 \%$. Sylhet has a moderate and hot climate. In summer more rainfall occurs than winter in Dhaka. The yearly mean temperature is $23.6^{\circ} \mathrm{C} \mid 74.5^{\circ} \mathrm{F}$ in Sylhet. Total Rainfall is $5048 \mathrm{~mm} \mid 198.7$ inches and annual mean humidity is $77 \%$. The climatic condition of Rangpur is also moderate and warm. Rainfall is more organized in summer than winter. The annual average temperature in Rangpur is $24.3^{\circ} \mathrm{C} \mid 75.7^{\circ} \mathrm{F}$. Total rainfall is $2497 \mathrm{~mm} \mid 98.3$ inches and yearly mean humidity is $79 \%$.
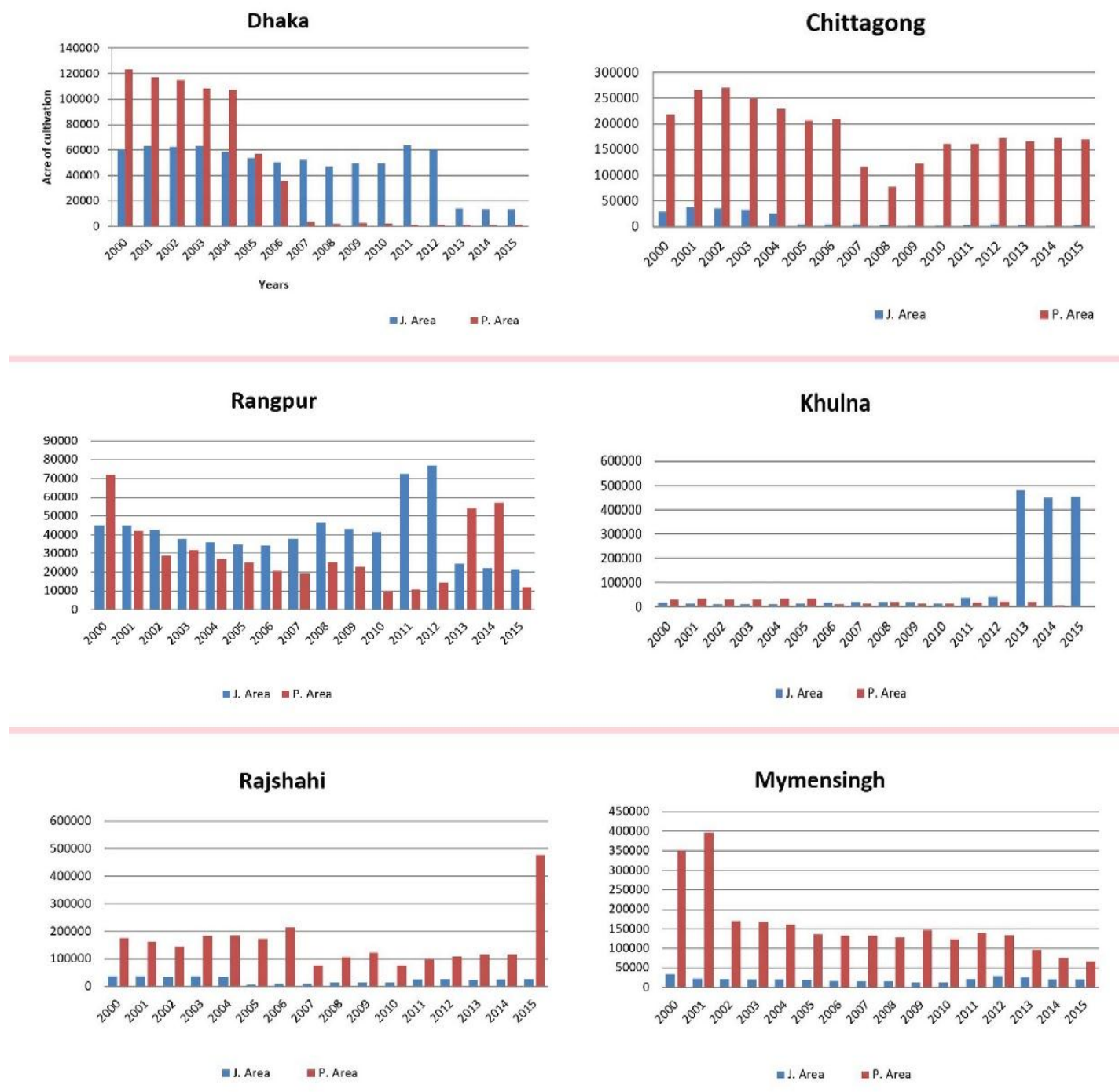

Sylet

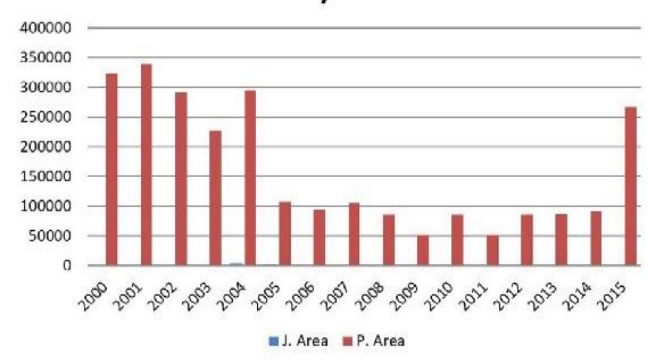

Fig. 3. Year based production in different regions (2000-2015) 
By analyzing the cultivated area of jute and paddy of 16 years from these selected regions. The obtained results show that the cultivation area of paddy in Dhaka, Chittagong, Rangpur, and Sylhet regions is comparatively higher than Khulna, Rajshahi, Mymensingh. However, in the last few years, the paddy cultivation area has declined in Dhaka and Sylhet regions. Among other regions, Rajshahi and Mymensingh have moderate paddy cultivation areas. The paddy cultivation area of the Khulna region is very low. On the other hand, analysis of jute cultivation area data shows that the jute cultivated area in Dhaka and Rangpur regions is much higher than other regions. However, the jute cultivation area in the Dhaka region has declined in the last few years. The jute cultivation area in the Khulna region has increased a bit in recent years. The jute cultivation area of residual regions is very low, especially in the Sylhet, the cultivation area is drastically reduced.

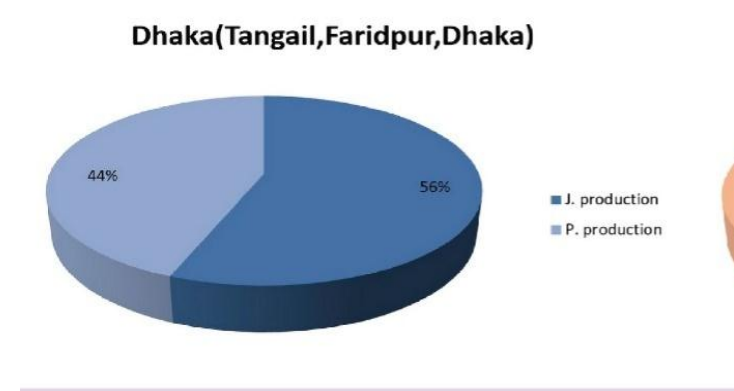

\section{Chittagong(Comilla,Chittagong)}

Rangpur(Dinajpur,Rangpur)
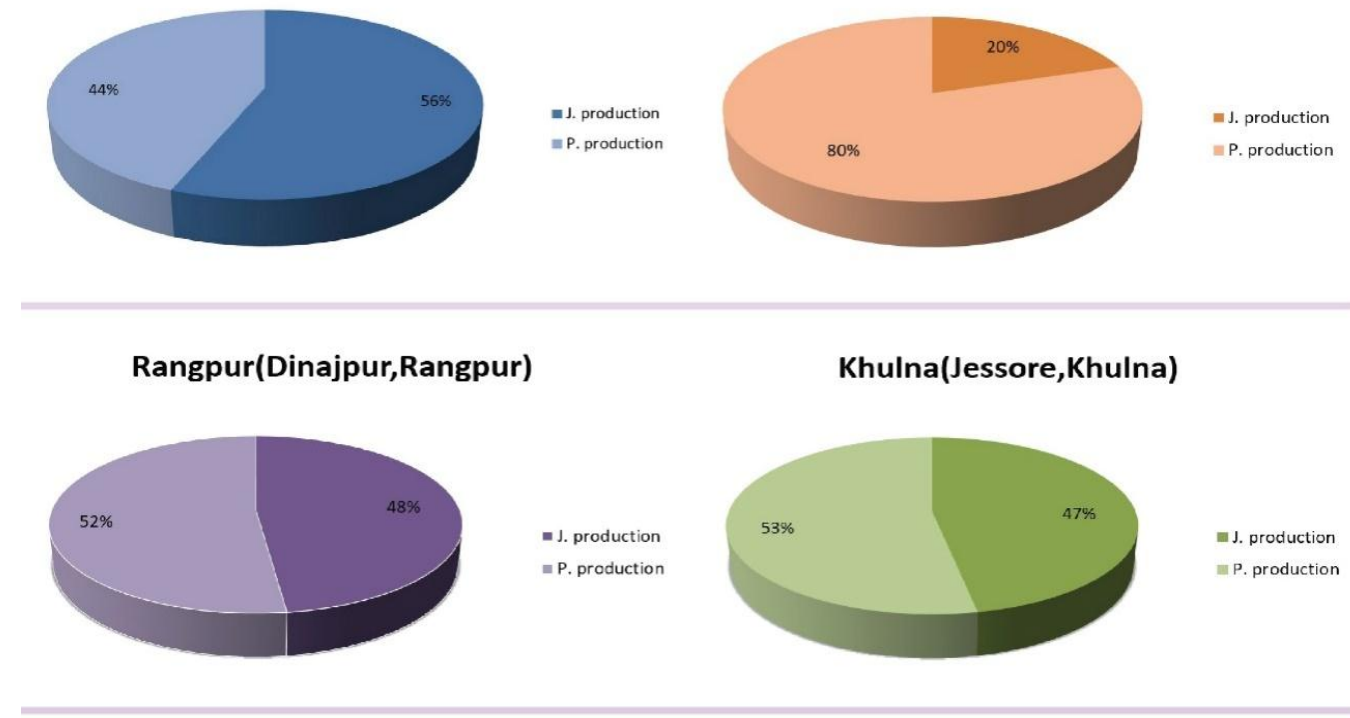

Khulna(Jessore,Khulna)

Rajshahi (Bogra,Rajshahi)

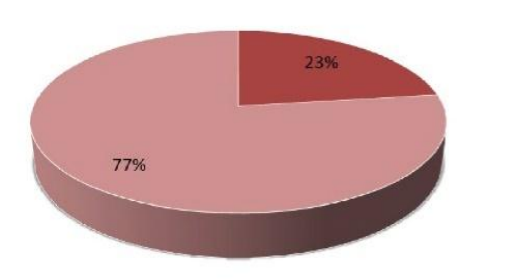

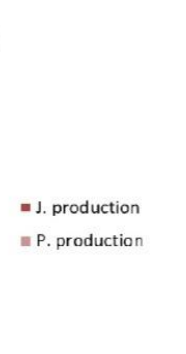

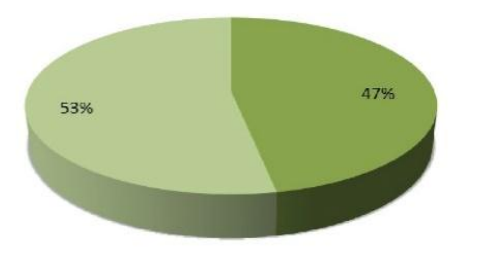

Im. production in. P. production

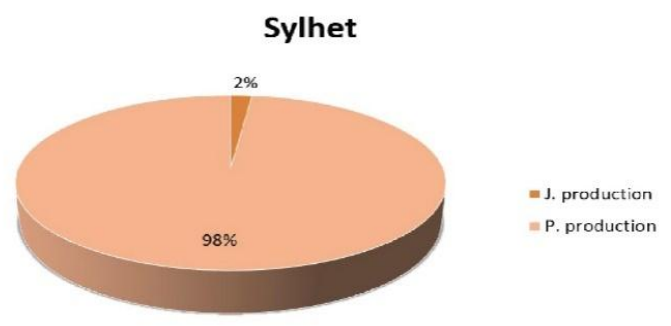

Fig .4. Pie Chart of Paddy and Jute production in seven areas [2000-2015]

The above pie charts exhibit the average paddy and jute production percentage in the 46 years among seven predetermined regions (Dhaka, Chittagong, Rangpur, Khulna, Rajshahi, Mymensingh, Sylhet). In these regions, the average production of paddy in the 46 years was $11,20,16,14,15,18$, and 22 percent respectively. Furthermore, throughout the 46 years, average jute production has been $89,80,84,86,85,82$, and 78 percent respectively in Dhaka, Chittagong, Rangpur, Khulna, Rajshahi, Mymensingh and Sylhet region respectively. The consequences show that the utmost paddy production and the minimum jute production are in the Sylhet region. Conversely, the Dhaka region has the utmost jute production and minimum paddy production. 


\subsection{Data extraction and pre-processing}

Farmers confront various issues in farming because of the absence of a precise notion of land and weather [29]. This paper has provided a solution to this problem. Data analysis has been identified as a way to solve this problem which is a huge contribution of information technology. As part of the plan, some methods have applied, one of which is: Production in an area must depend on precipitation, temperature, and relative humidity of an area [30]. The grains have picked on which the effect of the parameters (precipitation, temperature, and relative humidity) is noticeable. The climate has a more noticeable impact on the production of Jute(Corchorus spp.) and Paddy(Oryza sativa) [31, 32, 33]. The most significant places of Bangladesh are selected as study areas. Where all the data of 47 years (Production, the area of cultivation, rainfall, relative humidity, temperature) of 13 districts have been collected and the divisions have been given priority. Those Data has taken from different sources (local collection, websites, and data banks). Data has been used to establish a picture of overall jute and paddy production in 7 divisions across the country. For data analysis, a model has been developed. Data has sorted according to the following model for each district and division. The following is a sample model with only data of 3 years.

Table 2. Summary of the seven study areas with total production and parameters

\begin{tabular}{|c|c|c|c|c|c|c|}
\hline Areas & Years & $\begin{array}{l}\begin{array}{l}\text { J.Production } \\
\text { (bales/Acre) }\end{array} \\
\end{array}$ & $\begin{array}{l}\text { P.Production } \\
\text { (bales/acre) }\end{array}$ & Rainfall & Humidity & Temperature \\
\hline \multirow[t]{3}{*}{ Dhaka } & 2011 & 4.438606 & 2.604903547 & 1048 & 71.8 & 29.93 \\
\hline & 2012 & 3.94386 & 2.741578608 & 844 & 71.2 & 30.68 \\
\hline & 2013 & 4.153339 & 2.781369863 & 1063 & 70.6 & 30.66 \\
\hline \multirow[t]{3}{*}{ Chittagong } & 2011 & 4.05 & 4.014086 & 1074 & 81.2 & 29.13 \\
\hline & 2012 & 3.699916874 & 4.19523 & 1141 & 81.6 & 29.6 \\
\hline & 2013 & 3.460128617 & 4.453879 & 1015 & 81 & 29.55 \\
\hline \multirow[t]{3}{*}{ Rangpur } & 2011 & 4.27703 & 3.688722 & 984 & 78 & 29.195 \\
\hline & 2012 & 4.519692 & 5.027387 & 1086.5 & 74.9 & 29.68 \\
\hline & 2013 & 4.565693 & 2.606259 & 991 & 75.7 & 29.88 \\
\hline \multirow[t]{3}{*}{ Khulna } & 2011 & 5.218961 & 4.399472 & 883 & 77.3 & 30.6 \\
\hline & 2012 & 4.102175 & 4.57097 & 720 & 77.8 & 31.705 \\
\hline & 2013 & 4.754742 & 3.425117 & 918.5 & 77.7 & 30.835 \\
\hline \multirow[t]{3}{*}{ Rajshahi } & 2011 & 5.399992 & 4.004578 & 745 & 77 & 30.075 \\
\hline & 2012 & 5.85 & 4.531529 & 549 & 72.9 & 31.305 \\
\hline & 2013 & 5.270018 & 4.014068 & 586 & 75.2 & 30.775 \\
\hline \multirow[t]{3}{*}{ Mymenshing } & 2011 & 3.280005544 & 3.427252 & 1133 & 81 & 28.9 \\
\hline & 2012 & 3.630007992 & 3.725841 & 938 & 80.6 & 29.41 \\
\hline & 2013 & 3.650018918 & 3.564125 & 983 & 80.6 & 29.58 \\
\hline \multirow[t]{3}{*}{ Sylhet } & 2011 & 3.258258258 & 3.622389 & 1831 & 77.2 & 29.36 \\
\hline & 2012 & 3.523076923 & 4.194542 & 3051 & 78.2 & 29.64 \\
\hline & 2013 & 3.383977901 & 4.12872 & 2500 & 75.6 & 29.98 \\
\hline
\end{tabular}

At the first, data has arranged in ten columns (Areas, Years, Jute production area, Jute production, Rainfall, Relative humidity, Temperature, the paddy production area and paddy production).Data process steps as follow as:

Random data $<$ Data error fined $<$ Data localization $<$ Arrange for a significant method $<$ Final Dataset.

The unit of paddy production was tons while the unit of jute production was bales. For the convenience of Analysis, the production of paddy and jute has been calculated for every acre. For which a year's total crop production has been divided into the land for cultivation of that crop. In the raw data set, the data of those parameters (Rainfall, Relative humidity, and Temperature) are for the whole year. The study covered annual crops, so the average values of 5 months' rainfall, temperature, and humidity have been taken.

\subsection{Parameter compositing and structure extraction}

Rice is the staple food of about 165 million people of Bangladesh. After Paddy, Jute is the most pivotal cash crop and biodegradable natural fiber produced in Bangladesh [16].Consequently, Paddy and Jute are selected for this study. The worldwide crop production required to be double by 2050 to meet the demand of the increasing population [34]. The climate changing parameters are the major barriers to a vast amount of agricultural production. The most influencing parameters (Rainfall, Temperature and Relative Humidity) for the agriculture sector due to climate change have selected for this study. The production of Paddy and Jute relies on these three parameters, in every phase from seed sowing time to harvesting time (March to July). Therefore, the climatic data from March to July month is picked for the study. In this approach, the preprocessed data is combined with the climate changing parameters. So that the effects of climate change on crop production can be measured. 


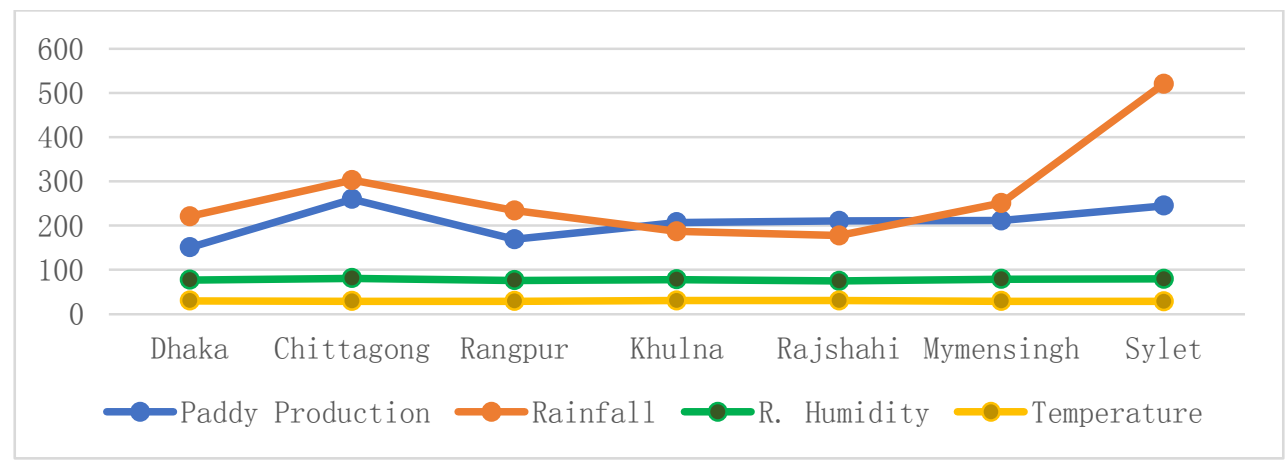

Fig .5. Climate Explained Paddy Production Variability

According to Fig 5. Paddy production indicated positive relationships with rainfall in most of the regions in Bangladesh. Khulna, Rajshahi and Rangpur regions showed the highest temperature and lowest rainfall and relative humidity causing lower paddy production than the other regions. Higher relative humidity and rainfall amount provoked an increase in production rates in Chittagong, Sylhet and Mymensingh region. The increasing temperature caused lower paddy production in the Dhaka region though rainfall and relative humidity were good.

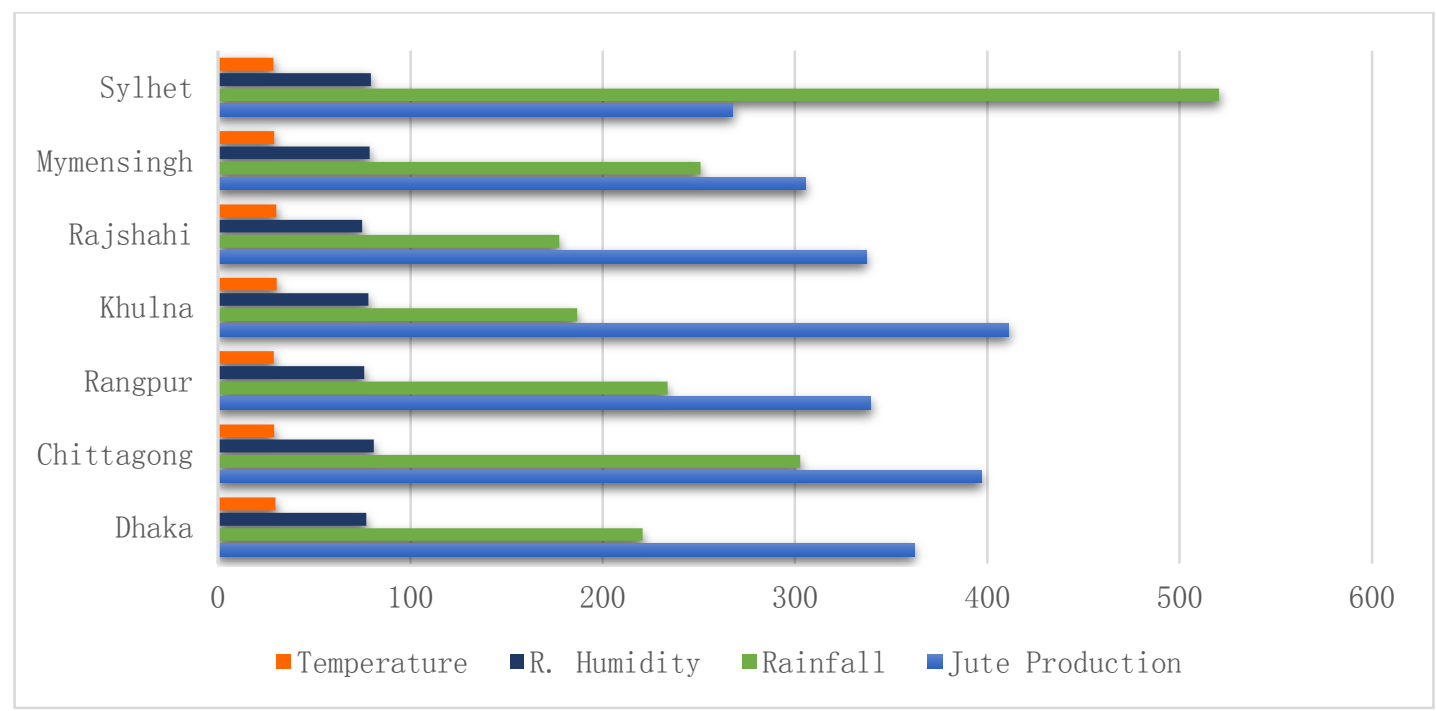

Fig. 6. Climate Explained Jute Production Variability

The effect of rainfall on Jute production is astonishing according to Fig 6. A moderate amount of rainfall is needed to achieve the highest yield of Jute. The highest rainfall area is Sylhet, where the production rate is the lowest. Moderate rainfall is showing positive relationship with jute production in Mymensingh, Rangpur, Dhaka and Chittagong regions. Rainfall and relative humidity are lowest but the temperature was the highest, causing a higher jute production rate in the Rajshahi region.

\section{Material and Method}

This paper has been employed two types of techniques. First, Bangladesh is presented with a farmland mapping. The mapping is based on data set Regression analysis. The next stage is to use the K-Means Clustering to implement crop pedicure.

\subsection{Cropland mapping}

The cropland mapping of Bangladesh is designed based on 2 important models. At first, diagrams have been made on each year's crop production data in each district. With the help of the diagram, the map design was easily found. Again using the key technique of the Multiple Linear Regression model has been used to make a complete cropland mapping from the obtaining data. This model is applied to explain the correlation among the variables. The model shows how much dependent variable changes for the independent variable. Here rainfall, relative humidity, and temperature all are independent variables, and crop production is a dependent variable. By using the relationship between parameters and crop production, cropland mapping has been done. The value of $\mathrm{R}^{2}$ is used to design the land mapping. Which is sowed the dimensions of the relationship between the variables. 

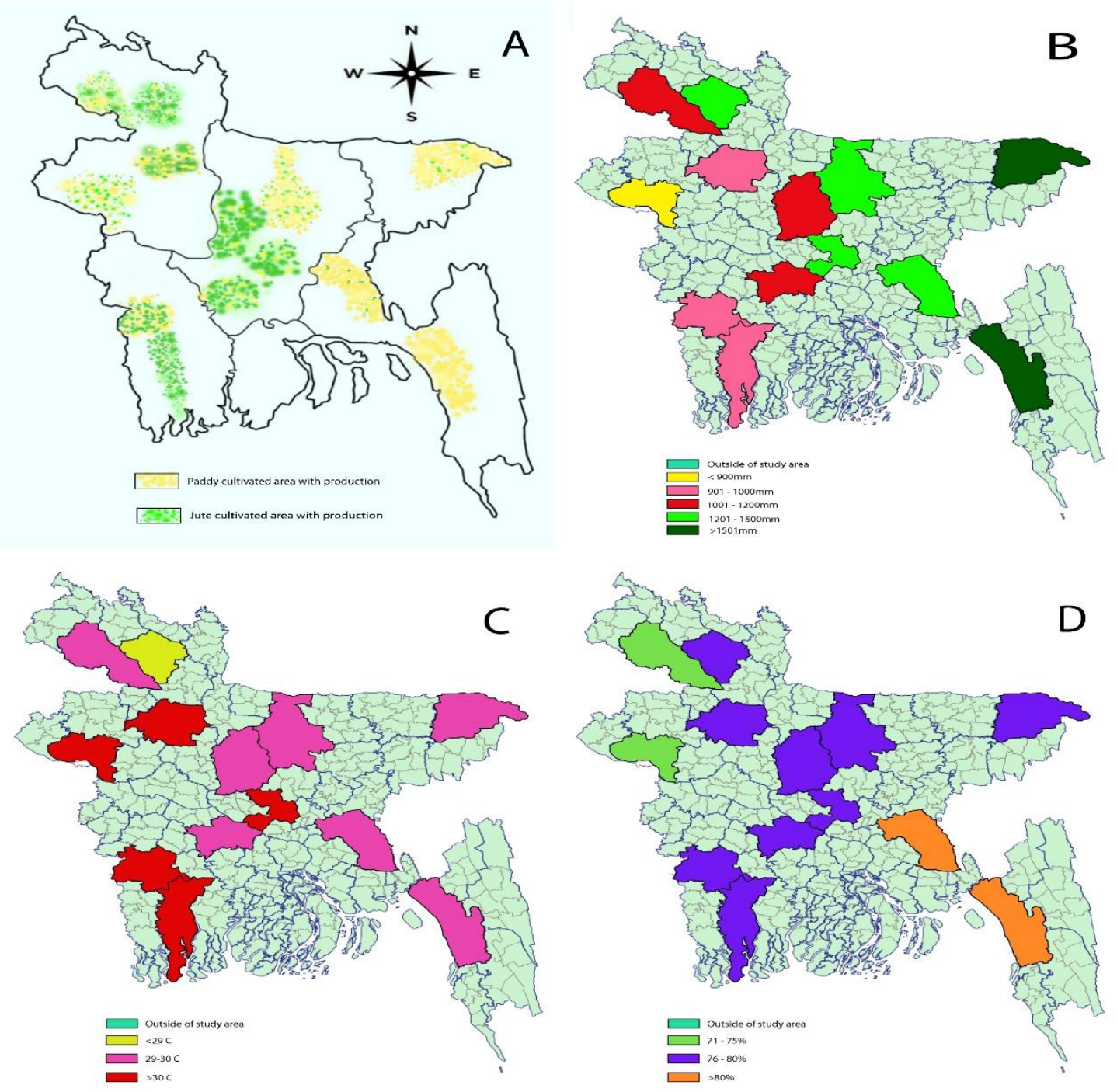

Fig. 7. Mapping of croplands obtained from data analysis

Specific 13 region's crop production, rainfall, temperature, and relative humidity have been analyzed by this land mapping. The above figure, i.e. (A, B, C, and D) showing the annual amount of crop production, rainfall, temperature, and humidity respectively in the different area in Bangladesh.

In Map A, the cultivated area and production amount of paddy and jute obtained in 13 designated regions are shown. The yellow color indicates the cultivated area and production of paddy. On the other hand, the green color indicates the cultivated area and production of jute. The map shows that Chittagong, Comilla, Mymensingh, and Sylhet regions have the highest cultivated area and production of paddy, but these regions have the lowest cultivated area and production of jute. Although paddy is cultivated jointly with jute in Dhaka, Faridpur, Khulna, Tangail, and Rangpur regions, the cultivated area and production of paddy are comparatively low. In addition, Dhaka, Faridpur, Khulna, Tangail, and Rangpur regions have the highest cultivated area and production of jute. Chittagong, Comilla, Mymensingh, and Sylhet regions have the lowest cultivated area and production of jute. Cultivated areas and production of paddy and jute in the Rajshahi, Bogra, Dinajpur, and Jessore regions are almost equal. The map shows that the Jessore region has a more cultivated area and production of jute than Rajshahi, Dinajpur and the Bogra region. Conversely, the cultivated area and production of paddy in the Rajshahi region are more than in the Jessore region.

In Map B, the annual total rainfall of different regions is shown. The vivid cyan color indicates outside of the study area. The colors: yellow, bright red, red, light green, and the dark green, show the amount of rainfall in different ranges $(<900 \mathrm{~mm}),(901-1000 \mathrm{~mm}),(1001-1200 \mathrm{~mm}),(1201-1500 \mathrm{~mm}),(>1501 \mathrm{~mm})$ respectively. The rainfall in Chittagong and Sylhet is more than $1501 \mathrm{~mm}$ which indicates the highest rainfall. Precipitation in Dhaka, Mymensingh, Comilla, and Rangpur is 1201-1500 mm. The amount of rainfall in Faridpur, Tangail, and Dinajpur is 1001-1200 mm. The rainfall in Khulna, Jessore, and Bogra is $901-1000 \mathrm{~mm}$. In Faridpur, Tangail, and Dinajpur occurs less rainfall than Dhaka, Mymensingh, Comilla, and Rangpur. On the other hand, Faridpur, Tangail, and Dinajpur obtained more rainfall 
than Khulna, Jessore, and the Bogra regions. The Rajshahi region obtained less than 900 mm of rainfall, which is the lowest rainfall in the country.

In Map C, the average temperature of different regions is indicated. Yellow, vivid pink, and red indicate the amount of temperature in different ranges $\left(<29^{\circ} \mathrm{C}\right),\left(29-30^{\circ} \mathrm{C}\right)$, and $\left(>30^{\circ} \mathrm{C}\right)$, respectively. The Rangpur region recorded the lowest average temperature of Bangladesh which is below $29^{\circ} \mathrm{C}$. The average temperature in Chittagong, Comilla, Faridpur, Tangail, Mymensingh, Sylhet, and Dinajpur is $29-30^{\circ} \mathrm{C}$. The average temperature in Dhaka, Khulna, Jessore, Rajshahi, and Bogra is above $30^{\circ} \mathrm{C}$. In other words, the highest temperature of the country is recorded in these regions. The average temperature in Chittagong, Comilla, Faridpur, Tangail, Mymensingh, Sylhet, and Dinajpur is lower than Dhaka, Khulna, Jessore, Rajshahi, and the Bogra regions.

In Map D, the amount of relative humidity of different regions is indicated. The bright green, vivid purple, and bright orange colors show the amount of humidity in different ranges (71-75\%), (76-80\%), and (> 80\%) respectively. The humidity of Chittagong and Comilla is more than $80 \%$, which means that the highest humidity of Bangladesh is recorded in these two regions. Humidity varies from $76 \%$ to $80 \%$ in Dhaka, Faridpur, Khulna, Jessore, Tangail, Mymensingh, Sylhet, Bogra, and the Rangpur regions. The humidity of these regions indicates that humidity is in the range of $76-80 \%$ in most parts of the country. The humidity of Rajshahi and Dinajpur is $71-745 \%$. That means the lowest humidity of the country is observed in these two regions.

\subsection{Regression analysis}

In this study, Multiple Linear Regression (MLR) has worked with a key technique to find out cropland mapping. For the cropland selection, production analysis and divided into separate land used this algorithm analysis. The key point of MLP is to develop a regression model to create and mapping help hand. To the data analysis, Rainfall, Humidity, Temperature are used as independent [35-36] variables where is production is dependent.

$$
y i=\beta 0+\beta 1 x i 1+\beta 2 x i 2+\ldots+\beta p x i p+\epsilon
$$

Equations (1) implies that multivariable where xi1, xip is the dependent variable and $y i$ mention the crop production. other $\beta$ values are all independent variables. $\epsilon$ is error rate from the linear data. $\beta 0$ is $y$-intercept (constant term) and $\beta p$ slope coefficients for each explanatory variable.
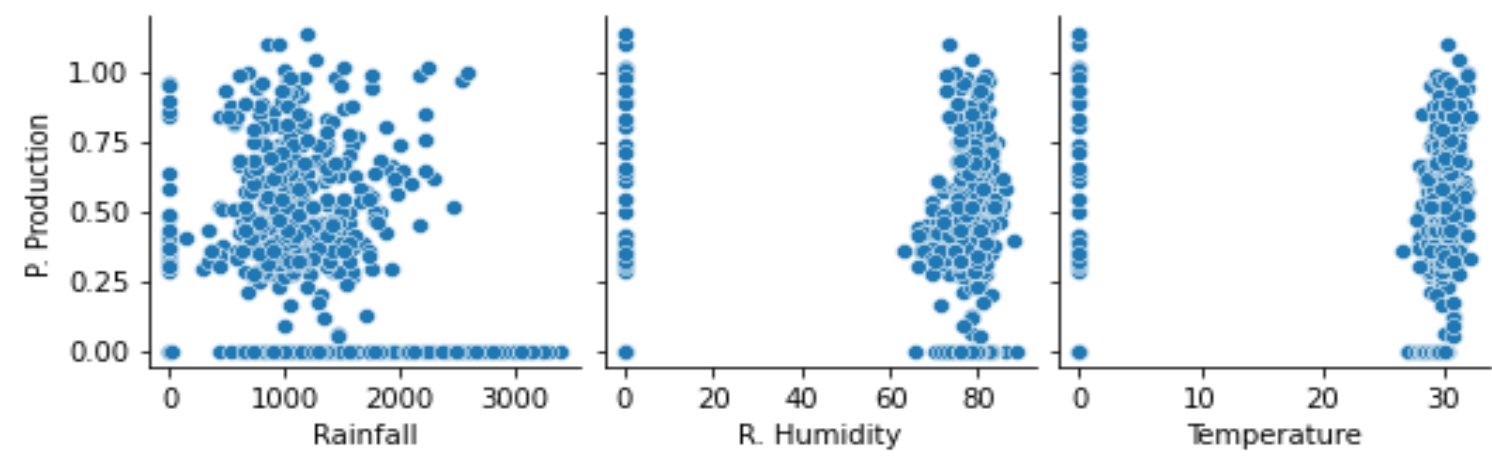

Fig.8. Production and another variable

Production forecasting system the coefficient of determination (R-squared) is a statistical metric that is used in this research as a model master. After train the data model, $\mathrm{R}^{2}=0.73$ which is very moderate and it is indicated the strong co-relation between each variable for production forecasting which is based on Rainfall, humidity and temperature.

\subsection{K-Means Clustering}

The principle of the K-Means clustering algorithm is that the mean of the documents allocated to the cluster can be represented by each of the k clusters assumed to be the centroid of that cluster. In our experiments, we used the second version of k-means algorithm is known as the incremental [37]. In the domain of prediction production (Jute and Paddy), online k-means performs better than the batch version. Initially, $k$ values are selected randomly from the corpus as the initial centroids. Then, the production is assigned iteratively and after each of the assignment to its nearest centroid, centroids are updated incrementally. When no reassignments of production occur, the iteration stops. The centroid vector $c$ of cluster $C$ of production has defined as follows:

$$
c=\Sigma d \epsilon C d|C|
$$

Where, $c$ is determined by the average weight of terms of the production in $C$. The similarity between a centroid vector $c$ and a production $D$ has defined by cosine similarity measure as: 

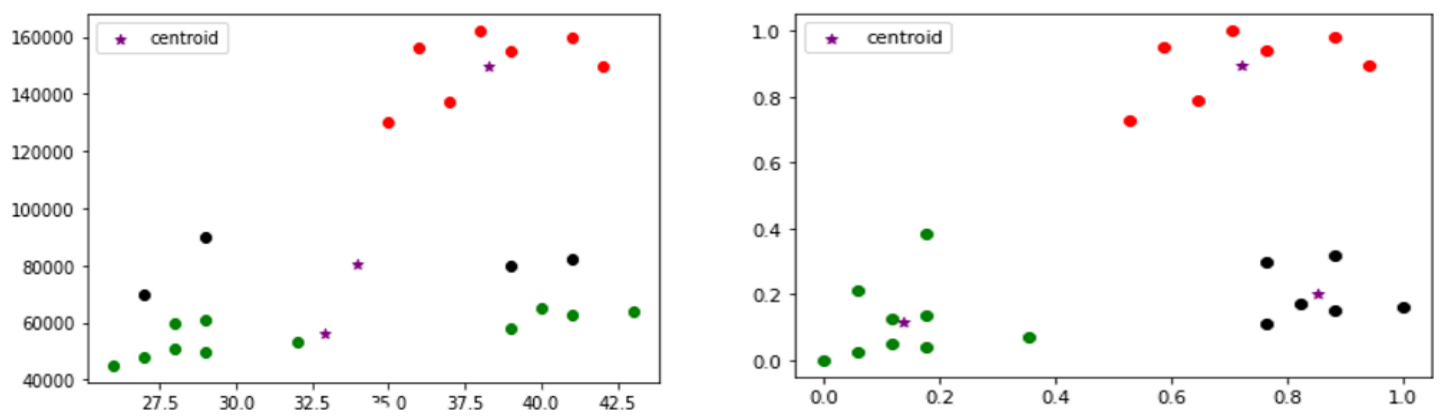

Fig.9. Centroid Analysis for production clustering

In this case, Cluster is used for the multivalued variable for the controlled find. Here we use Elbow Method Fig. 9. for the $\mathrm{K}$ value estimated. Different clusters indicate different variables like rainfall, humidity and temperature and Production analysis.

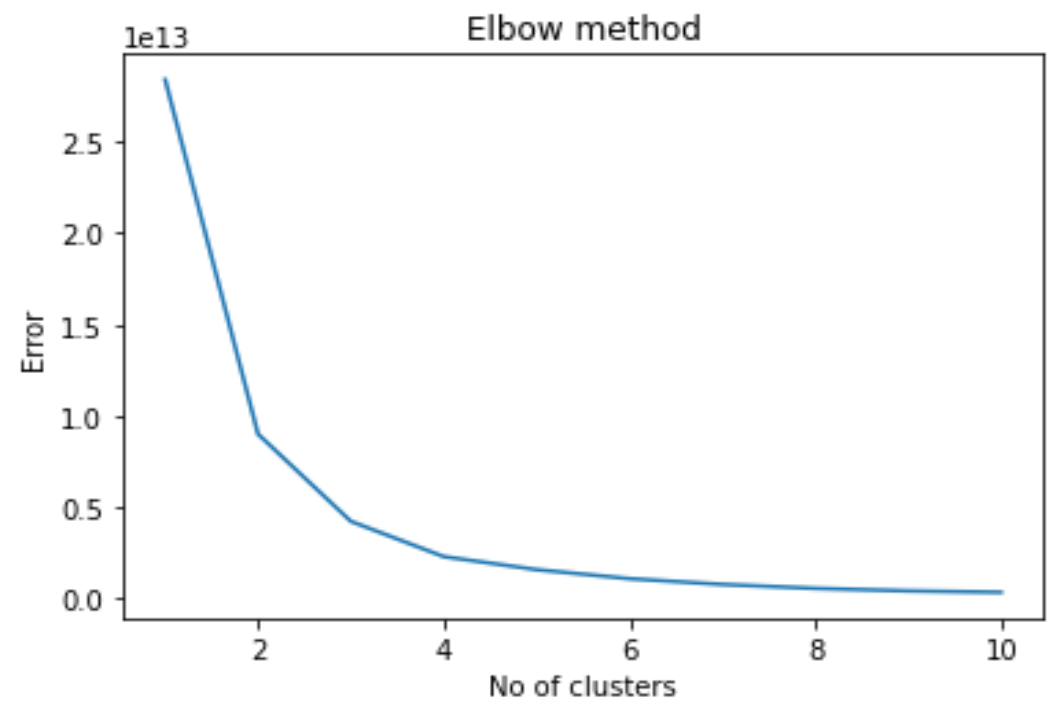

Fig.10. Elbow methodfor the K value estimated.

Clustering is deliberated as an unsupervised learning method since we applied it in the output of the clustering algorithm to evaluate our dataset performance and its destination find out and accurate accuracy with supervising and unsupervised learning.

\section{Results and Discussion}

This section implies that the impact on crop production (Jute, Paddy) which is dependent on the rainfall, humidity, temperature. Secondly, we examine the dependency and independence variable for impact on Agri production and forecasting in the next years. Table 3, is a sample of the random pickup year report which is based on equations (1), (2), (3). 
Table 3. Randomly Pickup relation and model accuracy

\begin{tabular}{|c|c|c|c|c|c|c|c|c|c|}
\hline Year & $\begin{array}{c}\text { Jute } \\
\text { Production } \\
\text { (Avg) }\end{array}$ & $\begin{array}{c}\text { Paddy } \\
\text { Production } \\
\text { (Avg) }\end{array}$ & $\begin{array}{c}\text { Rainfall } \\
\text { (Avg) }\end{array}$ & $\begin{array}{c}\text { Temperature } \\
\text { (Avg) }\end{array}$ & $\begin{array}{l}\text { Humidity } \\
\text { (Avg) }\end{array}$ & $\mathrm{R}^{2}$ Value & $\begin{array}{l}\text { Cluster } \\
\text { Model }\end{array}$ & $\begin{array}{c}\mathrm{P} . \\
\text { Variation }\end{array}$ & Relationship \\
\hline 2001 & 16.3 & 25.96 & 1331 & $33^{\circ} \mathrm{C}$ & 74.8 & 0.59 & Good & Yes & Strong \\
\hline 2002 & 15.26 & 40.56 & 1469 & $34^{\circ} \mathrm{C}$ & 73.6 & 0.67 & Good & Yes & Strong \\
\hline 2003 & 10.26 & 21.6 & 1785 & $35^{\circ} \mathrm{C}$ & 75.6 & 0.40 & Moderate & No & Moderate \\
\hline 2004 & 19.25 & 30.25 & 1269 & $30^{\circ} \mathrm{C}$ & 71.69 & .69 & Good & Yes & Strong \\
\hline 2005 & 18.12 & 29.26 & 1569 & $33^{\circ} \mathrm{C}$ & 71.02 & 0.56 & Good & Yes & Strong \\
\hline 2011 & 7.26 & 20.56 & 1356 & $36^{\circ} \mathrm{C}$ & 69.41 & 0.65 & Good & Yes & Strong \\
\hline 2012 & 10.33 & 23.58 & 1469 & $35^{\circ} \mathrm{C}$ & 66.9 & 0.76 & High & Yes & Strong \\
\hline 2013 & 11.69 & 29.25 & 1785 & $34^{\circ} \mathrm{C}$ & 86.25 & 0.66 & Moderate & Yes & Moderate \\
\hline 2014 & 9.5 & 29.69 & 2275 & $38^{\circ} \mathrm{C}$ & 90.25 & 0.39 & Good & No & Moderate \\
\hline 2015 & 17.69 & 38.25 & 1792 & $36^{\circ} \mathrm{C}$ & 85.56 & 0.58 & Good & Yes & Strong \\
\hline Unite & (bales/Acre) & (bales/acre) & $\mathrm{mm}$ & ${ }^{\circ} \mathrm{C}$ & $\%$ rh & $0<r<1$ & - & - & - \\
\hline
\end{tabular}

From the table, after the data analysis, we can see some different results that affect the production system. As expected, extreme rainfall and high temperature strongly affect agricultural productivity. An untactful environmental change on parameters (Rainfall, Humidity and Temperature) reduces agricultural productivity by $32-38 \%$. Where the co-efficient,

Table 4. Algorithms model accuracy and remark

\begin{tabular}{|ccccc|}
\hline Algorithm & Clustering & Regression & Model Accuracy & Remark \\
Supervised & - & MLR & $0.89 \%$ & High \\
Unsupervised & K-Means & - & $0.91 \%$ & High \\
Unsupervised & Hidden Markov & - & $0.68 \%$ & Moderate \\
Supervised & - & Decision Tree & $0.75 \%$ & Moderate \\
Supervised & - & LR & $0.68 \%$ & Moderate \\
\hline
\end{tabular}

Correlation $\left(\mathrm{R}^{2}\right)$ is good or strong that year production increases but if any parameter is not acting suitable or friendly the production is decreased as well.P. Variation is indicative of all parameters like rainfall, relative humidity and temperature relation based on an unsupervised clustering algorithm. According to Agro scientific report, for the best production (Jute) and cultivation need Temperature, Humidity and Rainfall $\left(18-35^{\circ} \mathrm{C}\right.$, Humidity above $80 \%$ and $1000-1500 \mathrm{~mm}$ ). Because of the smooth processing and data analysis in the future production forecasting system, we combined a supervised and unsupervised bot method. We applied more regression and clustering algorithms. In Table 4, shows the model accuracy for the forecasting system. After analyzing and discussing all the data, we can see that some elements of our environment are closely associated with the productivity of the crop. If any of these elements are affected, the system of production can undergo major changes. These excessive rains and droughts have a big impact, while excessive humidity is responsible for this rain control. In this study, multivariate algorithms and methods create a hypothesis of the production system that can change our agriculture crop production system. We can easily find next year's production system if we use this model. If we take some necessary steps about these parameters we can easily change our production system. 
Predication, gives an idea of which crop will be better in a specific weather combination. This results in no loss of money by cultivating the wrong crop. This will strengthen the economy of Bangladesh. Wrong crop cultivation will prevent the wastage of money. As a result of the cropland mapping, farmers will be able to know which crops are grown and yielded the most in their area. They will be motivated to cultivate that crop.

\section{Conclusion}

Since man has no control over nature, he has to work in agriculture in harmony with nature. Improvements in this agriculture field can be achieved only if changes in crop production can be brought about in conjunction with natural climate change. All types of crops don't grow well in all environments, so it is impossible to get good yields every time. The goal of this paper is to improve the living standards of farmers by solving all these problems. This paper tries to explain the relationship between rainfall, temperature, and humidity with jute and paddy production. We applied two methods (Regression analysis and K-Means Clustering) to measure the depth of these relationships using its dataset which comes from the Bangladesh Bureau of Statistics (BBS) and The Data World. From the first data obtained, rainfall, temperature, and humidity of each month have been analyzed separately. Secondly, how much land and how much jute and paddy is cultivated in different parts of the country have been collected. Thirdly, a final result brings out obtained by analyzing all the data. By analyzing those data Changes in crop cultivation are observed in a given area over the last 46 years. The results are shown in the precipitation, temperature, and humidity review of crop productivity in a certain field. For example, rainfall is good for jute production, but due to excess rainfall, jute production in Sylhet is not much. A cropland mapping of Bangladesh has been made through the collection of data analysis. Through which a person can easily understand in which region the selected crop grows well and will get a detailed idea about that. A prediction has been given as to which weather combination will give a better yield in the future. Through this paper, a farmer in a village will be able to select the right crop for his cultivation and have an idea about the yield of that crop. These results will have a meaningful impression on Bangladesh's agricultural infrastructure and development policies.

\section{Acknowledgment}

The authors are thankful to Bangladesh Agricultural University's Extension department for helping sort datasets and Daffodil International University Lab for analyzing these data. Hajee Mohammad Danesh Science \& Technology University department and Patuakhali Science and Technology University faculty also support us for this analysis.

\section{References}

[1] Salau, O.R., Momoh, M., Olaleye, O.A. and Owoeye, R.S., 2016. Effects of changes in temperature, rainfall and relative humidity on banana production in Ondo State, Nigeria. World Scientific News, (44), pp.143-154.

[2] Al Mamun, M.R., Shahed, A.B.M. and Tamanna, T.A., 2018. Identification of Hindrances to Adapt Agricultural Machinery in Selected Areas of Bangladesh.

[3] Islam, M.S. and Shirazul, D., 2009, October. Farm mechanization for sustainable agriculture in Bangladesh: Problems and prospects. In 5th APCAEM Technical Committee Meeting and the Expert Group Meeting on Application of Agricultural Machinery for Sustainable Agriculture. United Nations Asian and Pacific Centre for Agricultural Engineering and Machinery, Manila, Philippines (pp. 14-16).

[4] Vallat, A., Gu, H. and Dorn, S., 2005. How rainfall, relative humidity and temperature influence volatile emissions from apple trees in situ. Phytochemistry, 66(13), pp.1540-1550.

[5] Hastorf, C.A., 1988. The use of paleoethnobotanical data in prehistoric studies of crop production, processing, and consumption. Current paleoethnobotany: Analytical methods and cultural interpretations of archaeological plant remains, pp.119-144.

[6] Abou-Hadid, A.F., 1997, November. The use of weather data for crop production and protection. In International Symposium Greenhouse Management for Better Yield \& Quality in Mild Winter Climates 491 (pp. 169-176).

[7] Rahman, S. and Anik, A.R., 2020. Productivity and efficiency impact of climate change and agroecology on Bangladesh agriculture. Land Use Policy, 94, p.104507.

[8] Sikder, R. and Xiaoying, J., 2014. Climate change impact and agriculture of Bangladesh. Journal of Environment and Earth Science, 4(1), pp.35-40.

[9] Rahman, M., 2017. Role of agriculture in Bangladesh economy: uncovering the problems and challenges. International Journal of Business and Management Invention, 6(7).

[10] Von Braun, J., De Haen, H. and Blanken, J., 1991. Commercialization of agriculture under population pressure: Effects on production, consumption, and nutrition in Rwanda (Vol. 85). Intl Food Policy Res Inst.

[11] Ndamani, F. and Watanabe, T., 2015. Influences of rainfall on crop production and suggestions for adaptation. International journal of agricultural sciences, 5(1), pp.367-374.

[12] Ramírez Villegas, J. and Thornton, P.K., 2015. Climate change impacts on African crop production. CCAFS Working Paper.

[13] David Makowski, Elodie Marajo-Petitzon, Jean-Louis Durand, Tamara Ben-Ari., 2020, Quantitative synthesis of temperature, $\mathrm{CO} 2$, rainfall, and adaptation effects on global crop yields. European Journal of Agronomy, Volume 115, 126041

[14] Kukal, M.S., Irmak, S., 2018, Climate-Driven Crop Yield and Yield Variability and Climate Change Impacts on the U.S. Great Plains Agricultural Production. Sci Rep 8, 3450. 
[15] Kogo, B.K., Kumar, L. \&Koech, R., 2021, Climate change and variability in Kenya: a review of impacts on agriculture and food security. Environ Dev Sustain 23, 23-43.

[16] Pathak TB, Maskey ML, Dahlberg JA, Kearns F, Bali KM, Zaccaria D. 2018, Climate Change Trends and Impacts on California Agriculture: A Detailed Review. Agronomy; 8(3):25.

[17] Rahman, M.A., Kang, S., Nagabhatla, N. et al., 2017, Impacts of temperature and rainfall variation on rice productivity in major ecosystems of Bangladesh. Agric\& Food Secur 6, 10.

[18] AshwaniPareek, Om ParkashDhankher, Christine H Foyer, 7 January 2020, Mitigating the impact of climate change on plant productivity and ecosystem sustainability. Journal of Experimental Botany, Volume 71, Issue 2, Pages 451-456.

[19] Sanzidur Rahman, Asif Reza Anik, 2020, Productivity and efficiency impact of climate change and agroec ology on Bangladesh agriculture, Land Use Policy, Volume 94, 104507

[20] Ali, S., Liu, Y., Ishaq, M., Shah, T., Ilyas, A. and Din, I.U., 2017. Climate change and its impact on the yield of major food crops: Evidence from Pakistan. Foods, 6(6), p.39.

[21] Zhao, C., Liu, B., Piao, S., Wang, X., Lobell, D.B., Huang, Y., Huang, M., Yao, Y., Bassu, S., Ciais, P. and Durand, J.L., 2017. Temperature increase reduces global yields of major crops in four independent estimates. Proceedings of the National Academy of Sciences, 114(35), pp.9326-9331.

[22] Islam, M.S., Roy, S., Afrin, R. and Mia, M.Y., 2020. Influence of climate-induced disasters and climatic variability on cropping pattern and crop production in Bangladesh. Environment, Development, and Sustainability, 22(7), pp.6709-6726.

[23] Zhang, J., Ren, W., An, P., Pan, Z., Wang, L., Dong, Z., He, D., Yang, J., Pan, S. and Tian, H., 2015. Responses of crop water use efficiency to climate change and agronomic measures in the semiarid area of northern China. PloS one, 10(9), p.e0137409.

[24] Barma, N.C.D., Hossain, A., Hakim, M.A., Mottaleb, K.A., Alam, M.A., Reza, M.M.A. and Rohman, M.M., 2019. Progress and challenges of wheat production in the era of climate change: a Bangladesh perspective. In Wheat production in changing environments (pp. 615-679). Springer, Singapore.

[25] Hossain, M.S., Arshad, M., Qian, L., Kächele, H., Khan, I., Islam, M.D.I. and Mahboob, M.G., 2020. Climate change impacts farmland value in Bangladesh. Ecological indicators, 112, p.106181.

[26] Yadav, P., Jaiswal, D.K. and Sinha, R.K., 2021. Climate change: Impact on agricultural production and sustainable mitigation. In Global Climate Change (pp. 151-174). Elsevier.

[27] Von Storch, H. and Stehr, N., 2006. Anthropogenic climate change: a reason for concern since the 18th century and earlier. GeografiskaAnnaler: Series A, Physical Geography, 88(2), pp.107-113.

[28] Rojas, J.A.R., Kery, M.B., Rosenthal, S. and Dey, A., 2017, October. Sampling techniques to improve big data exploration. In 2017 IEEE 7th symposium on large data analysis and visualization (LDAV) (pp. 26-35). IEEE.

[29] Allen, D.W. and Lueck, D., 2004. The nature of the farm: contracts, risk, and organization in agriculture. MIT press.

[30] Monteith, J.L., 1977. Climate and the efficiency of crop production in Britain. Philosophical Transactions of the Royal Society of London. B, Biological Sciences, 281(980), pp.277-294.

[31] Ahmad, J., Alam, D. and Haseen, M.S., 2011. Impact of climate change on agriculture and food security in India. International Journal of Agriculture, Environment and Biotechnology, 4(2), pp.129-137.

[32] Giri, A.K., Banerjee, B.N., Mukherjee, A.K. and Sain, K., 1979. Impact of Variations in Rainfall and Weather Conditions on Production of Crops in West Bengal. Economic Affairs (Calcutta), 24(1), p.57.

[33] Sarkar, S. and Majumdar, B., 2016. Present Status of Jute Production and Technological and Social Interventions Needed for Making Jute Agriculture Sustainable and Remunerative in West Bengal.

[34] Islam, M.M. and Ali, M.S., 2017. Economic importance of jute in Bangladesh: production, research achievements and diversification. International Journal of Economic Theory and Application, 4(6), pp.45-57.

[35] I. Salehin, I. M. Talha, M. Mehedi Hasan, S. T. Dip, M. Saifuzzaman and N. N. Moon, "An Artificial Intelligence Based Rainfall Prediction Using LSTM and Neural Network," 2020 IEEE International Women in Engineering (WIE) Conference on Electrical and Computer Engineering (WIECON-ECE), 2020, pp. 5-8, doi: 10.1109/WIECON-ECE52138.2020.9398022.

[36] I. Salehin, I. M. Talha, M. Saifuzzaman, N. N. Moon and F. N. Nur, "An Advanced Method of Treating Agricultural Crops Using Image Processing Algorithms and Image Data Processing Systems," 2020 IEEE 5th International Conference on Computing Communication and Automation (ICCCA), 2020, pp. 720-724, doi: 10.1109/ICCCA49541.2020.9250839.

[37] M. Talha, I. Salehin, S. C. Debnath, M. Saifuzzaman, N. N. Moon and F. N. Nur, "Human Behaviour Impact to Use of Smartphones with the Python Implementation Using Naive Bayesian," 2020 11th International Conference on Computing, Communication and Networking Technologies (ICCCNT), 2020, pp. 1-6, doi: 10.1109/ICCCNT49239.2020.9225620.

\section{Authors' Profiles}

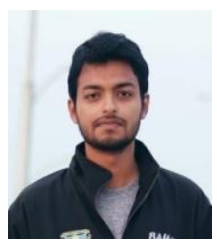

Prodipto Bishnu Angon studies Agriculture at Bangladesh Agricultural University. Main Interested research fields are Climate change, Insect detection, Plant stress detection, Environmental sector, Data mining and IoT. His research interests include Genetics and plant breeding. 


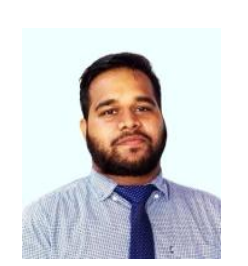

Imrus Salehin completed his BSc. in Computer Science and Engineering in 2021 from Daffodil International University. Main Interested research fields are Image Processing, Machine Learning, Data Mining and IoT. His research interests include Data science and Computer vision. Moreover, He has published his research works in reputed national and International Journals \& Conferences and served as a reviewer in multiple reputed Conferences and Journals

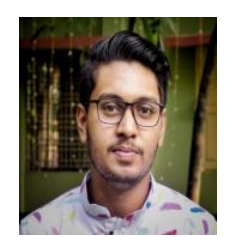

Md. Mahbubur Rahman Khan is an undergraduate student at the Department of Food and Process Engineering,HSTU,Dinajpur. He is currently researching Human Gut Microbiota, Probiotic Food and Plant Endophytes.

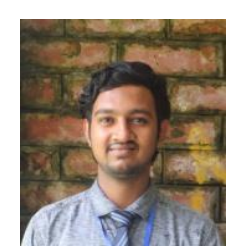

Sujit Mondal studies Agriculture at Patuakhali Science and Technology University. His main Interested research fields are microorganisms, plant breeding, weed science, fungi, parasites, plant disease and Entomology. He is also interested in research in climate change and environmental sectors.

How to cite this paper: Prodipto Bishnu Angon, Imrus Salehin, Md. Mahbubur Rahman Khan, Sujit Mondal, " Cropland Mapping Expansion for Production Forecast: Rainfall, Relative Humidity and Temperature Estimation ", International Journal of Engineering and Manufacturing (IJEM), Vol.11, No.5, pp. 25-40, 2021. DOI: 10.5815/ijem.2021.05.03 